\title{
NOTA SOBRE A QUESTÃO DOS UNIVERSAIS EM TOMÁS DE AQUINO
}

\author{
Carlos A. R. do Nascimento \\ Universidad de Campinas, Sao Paulo (Brasil)
}

\section{RESUMEN}

En esta nota, el autor recuerda cómo Santo Tomás de Aquino se ha ocupado del problema de los universales, señala los textos más importantes en que aborda tal cuestión y formula algunas observaciones en torno a ellos. Finalmente, traduce al portugués uno de estos textos.

Palabras clave: Santo Tomás, Aristóteles, universales...

\begin{abstract}
In this note, the author remembers how Saint Thomas of Aquino has dealt with the problem of universals, he points out the most important texts in that Aquinas approaches such a question and he formulates some observations with regard to them. Finally, he translates one of these texts.
\end{abstract}

Key words: Saint Thomas, Aristote, Universals.

A querela dos universais atravessa de algum modo todo o pensamento medieval. Ela reveste certamente matizes próprios conforme a época, o pensador e o material de que ele dispunha. Tomás de Aquino não deixou de lado este tópico. Sua maneira de abordá-lo, talvez característica do século XIII, é pôr em relevo as condições ontológicas que possibilitam a formação dos universais. Tal abordagem é constante em seus textos, escalonando-se desde $O$ ente e a essência até os comentários aristotélicos sobre o Tratado da alma e a Metafísica.

É possível enumerar sumariamente e sem pretensão de completude uma dezena de passagens: 1) O ente e a essência, cap. 3; 2) Quodlibet VIII, artigo 1;3) Questão disputada sobre o poder de Deus, Questão 5, artigo 9, resposta ao argumento 16; 4) Suma de teologia, Primeira parte, Questão 85, artigo 2, ad 2m; 5) Idem, Questão 85, artigo 3, ad $1 \mathrm{~m}$ e ad 4m; 6) Idem, Primeira parte da segunda parte, Questão 29, artigo 6; 7) Sentença do livro Sobre a alma, liv. I, cap. 1, p.7, lin. 213-230; 8) Idem, liv. II, cap. 12, p. 115-116, lin. 95-151; 9) Sentença do livro da Metafísica, Liv. I, cap. 10, no 158; 10) Idem, liv. VII, cap. 13, $\mathrm{n}^{\circ} 1570$. 
Podemos de início fazer algumas observações sobre estes textos. Os dois primeiros citam explicitamente Avicena (Metafísica), enumerando o opúsculo sobre $O$ ente e a essência, em primeiro lugar a natureza considerada de maneira absoluta de acordo com sua noção própria; passando-se em seguida à natureza de acordo com o ser que tem nos sigulares e no intelecto. O Quodlibet VIII, no entanto, inicia pela natureza considerada de acordo com o ser que tem nos singulares, passa à sua consideração de acordo com o ser inteligível no intelecto e termina com a consideração absoluta da natureza, na medida em que faz abstração do duplo ser mencionado.

O texto da Questão disputada sobre o poder de Deus, bem como os enumerados em seguida, não citam Avicena, mas supõem a tríplice consideração da essência presente nos dois textos anteriormente mencionados. Tem esta resposta da Questão disputada sobre o poder de Deus o caráter de um resumo se comparada com as exposições mais detalhadas dos textos enumerados antes dela.

As passagens da Suma supõem a tríplice consideração da essência, formulando-a através da distinção entre 1) a natureza da coisa, 2) o ser inteligida ou abstraída ou dotada de universalidade ( intenção da universalidade) e 3) seu ser nos singulares. Pode-se dizer que estas passagens da Suma combinam a distinção aviceniana com a distinção abelardiana entre modo de ser e modo de inteligir, utilizada na Suma, Primeira parte, Questão 84, artigos 1 e 2. Observe-se ainda que Ia, Q. 85, a. 3 , ad $1 \mathrm{~m}$ cita o livro Sobre a alma (liv. I) e que Ia, Q. 85, a. 3, ad. $4 \mathrm{~m}$ remete à Metafísica (liv. VII), havendo também um estreito paralelismo entre Ia Iae, Q. 29, a. 6 e Ia, Q. 85, a. 3, ad $1 \mathrm{~m}$.

Os dois textos da Sentença do livro Sobre a alma são paralelos, sendo o segundo mais explícito que o primeiro. Aflora neles a polêmica antiplatônica já presente em Ia, Q.85, a.3, ad $1 \mathrm{~m}$ e ad $4 \mathrm{~m}$, que reaparecerá nos textos da Sentença do livro da Metafisica. O vocabulário dos textos da Sentença do livro Sobre a alma é mais ontológico e mais próximo de Avicena, distinguindo a natureza e seu duplo ser, não havendo traços do vocabulário modista abelardiano.

Nas passagens citadas da Sentença do livro da Metafísica a polêmica antiplatônica passa ao primeiro plano e volta à tona, na passagem do Livro I, o vocabulário modista, recorrendo-se ao princípio de recepção neoplatônico ("omne quod est in aliquo, est pẹr modum ejus in quo est"), como acontecia na Suma (Ia, Q. 84, a. 1 e 2; Q. 85, a. 5, ad 3m).

Este percurso, ainda que sumário, dos textos enumerados de início parece confirmar que Tomás de Aquino recorre de maneira constante à distinção aviceniana da consideração da essência em si mesma e segundo o ser que tem nas coisas materiais ou no intelecto humano, sendo então singularizada nas coisas e universalizada no intelecto. Tomás combina tal distinção com outra, a saber, a distinção entre o modo de ser das coisas (material, singular e contingente) e o modo de serem por nós inteligidas (imaterial, universal e necessário). $\mathrm{O}$ que justifica em última análise esta disparidade é o princípio de recepção. O recurso aos dois pares de consideração e ao princípio citado permite a Tomás de Aquino fundamentar sua concepção realista do conhecimento intelectual humano, tendo em conta tanto as características do ente material como do conhecimento intelectual.

ANEXO - SENTENÇA DO LIVRO SOBRE A ALMA, liv. II, Cap. XII, pp. 115-116, lins. 95-151

A respeito do segundo [como os universais estão na alma] cabe considerar que o universal pode ser tomado de dois modos. De um primeiro modo, a própria natureza comum, na medida em que subjaz à noção [intentio] de universalidade, pode ser dita universal; de outro modo, de acordo con- 
sigo mesma. Como também o branco pode ser tomado de dois modos: ou aquilo a que acontece ser branco, ou o mesmo, na medida em que está sob a brancura. Ora, a própria natureza à qual advém a noção de universalidade, por exemplo a natureza do homem, tem um duplo ser: um material na medida em que é na matéria natural e outro imaterial na medida em que é no intelecto. Então, na medida em que tem o ser na matéria natural, não lhe pode advir a noção de universalidade porque é individuada pela matéria; a noção de universalidade advém-lhe, pois, na medida em que é abstraída da matéria individual. Ora, não é possível que seja abstraída realmente da matéria individual, como sustentaram os platônicos, pois o homem não é senão nestas carnes e nestes ossos, como 0 Filósofo prova no VII da Metafísica [7, 1034 a 5-8]. Resta, pois, que a natureza humana não tem ser à parte dos princípios individuantes a não ser apenas no intelecto. No entanto, o intelecto não é falso apreendendo a natureza comum à parte dos princípios individuantes, sem os quais não pode ser na natureza das coisas; com efeito, o intelecto não apreende que a natureza comum é sem os princípios individuantes, mas apreende a natureza comum, não apreendendo os princípios individuantes e isto não é falso, ao passo que o primeiro seria falso. Assim como, se separasse a brancura de um homem branco de tal modo que inteligisse que ele não é branco, a apreensão seria falsa; mas se separạsse a brancura do homem de tal modo que apreendesse o homem, nada apreendendo de sua brancura, a apreensão não seria falsa. De fato, não se exige para a verdade da apreensão que quem apreende alguma coisa apreenda tudo que está presente nela. Assim, portanto, o intelecto abstrai sem falsidade o gênero das espécies, na medida em que intelige a natureza do gênero não inteligindo as diferenças e de modo semelhante abstrai a espécie dos indivíduos na medida em que intelige a natureza da espécie não inteligindo os princípios individuais. Portanto, fica assim manifesto que a noção da universalidade não pode ser atribuída à natureza comum senão de acordo com o ser que tem no intelecto; pois, somente assim é uno de muitos, conforme é inteligida à parte dos princípios pelos quais o uno divide-se em muitos. Donde restar que os universais na medida em que são universais não são senão na alma, mas as próprias naturezas às quais advém a noção de universalidade são nas coisas, Por isso, os nomes comuns que significam as próprias naturezas predicam-se dos indivíduos, mas não os nomes que significam as noções lógicas; com efeito, Sócrates é homem, mas não é espécie, embora homem seja espécie.

Carlos A. R. do Nascimento Universidade de Campinas, SP (Brasil)

Rua Mateus Grou, 345 05415-050 Sao Paulo, SP (Brasil)

\section{REFERÊNCIAS BIBLIOGRÁFICAS}

O livro de A. De Libera, La querelle des universaux, Paris, Seuil, 1996 oferece um excelente panorama da querela. Para Tomás de Aquino, ver especialmente as pp. 277-283.

Para a distinção entre modo de inteligir e modo de subsistir em Abelardo, ver Logica "Ingredientibus", Ed. B. Geyer, Beiträge zur Geschichte der Philosophie des Mittelalters, Münster, 1919, Band XXI, Heft 1, p.25.

Utilizamos as seguintes edições das obras de Tomás de Aquino:

- "De ente et essentia". In: Sancti Thomae de Aquino opera omnia. Roma: Commissio Leonina; Paris: Ed. Du Cerf, 1976, tomo 43, p. 315-81. 
— "Quaestiones de quolibet". In: Ibidem, 1996, tomo 25, v.1.

— "Quaestio disputata De potentia Dei". In: Quaestiones disputatae. Torino: Marietti, 1953, v. 2, p. 7-276.

- Summa Theologiae. Roma: Paulinas, 1962.

- "Sententia libri De anima". In: Sancti Thomae de Aquino opera omnia. Roma: Commissio Leonina; Paris: Ed. Du Cerf, 1985, tomo 41, v. 1.

- In duodecim libros Metaphysicorum Aristotelis expositio. Torino: Marietti, 1950.

Os textos de Avicena podem ser encontrados em Le De ente et essentia de S. Thomas d'Aquin. Texte établit d'après les manuscrits parisiens, introduction, notes et études historiques par M.-D. Roland-Gosselin. Paris: J. Vrin, 1948. Pode-se consultar também Avicenna Latinus, Liber de Philosophia Prima sive Scientia Divina, Edition critique de la traduction latine médiévale par S. Van Riet. Louvain: E. Peeters; Leiden: E.J. Brill, 1980, 3 vols; La métaphysique du Shifa, Trad. G.C. Anawati. Paris: J. Vrin, 1985, 2 vols. Tradução de alguns extratos em Rafael Ramón Guerrero, Avicena, Madrid, Ed. Del Orto, 1994, especialmente p. 6263 (texto 10) e p. 71-72. 